\title{
Adrenergic receptor genotypes influence postoperative outcomes in infants in the Single-Ventricle Reconstruction Trial
}

\author{
Ronand Ramroop, MD, ${ }^{\mathrm{a}}$ George Manase, BSc, ${ }^{\mathrm{a}}$ Danny Lu, MSc, ${ }^{\mathrm{a}}$ Dorin Manase, BSc, ${ }^{\mathrm{a}}$ Shan Chen, MSc, \\ Richard Kim, MD, ${ }^{\mathrm{c}}$ Teresa Lee, MD, ${ }^{\mathrm{d}}$ William T. Mahle, MD, ${ }^{\mathrm{e}}$ Kimberly McHugh, MD, ${ }^{\mathrm{f}}$ \\ Mike Mitchell, MD, ${ }^{\mathrm{g}}$ Martin Tristani-Firouzi, MD, ${ }^{\mathrm{h}}$ Stephanie B. Wechsler, MD, ${ }^{\mathrm{i}}$ Nicole S. Wilder, MD, \\ Victor Zak, PhD, ${ }^{\mathrm{b}}$ Myriam Lafreniere-Roula, PhD, ${ }^{\mathrm{k}}$ Jane W. Newburger, MD, ${ }^{1}$ J. William Gaynor, MD, ${ }^{\mathrm{m}}$ \\ Mark W. Russell, MD, ${ }^{j}$ and Seema Mital, MD ${ }^{\mathrm{a}}$
}

\section{ABSTRACT}

Objectives: Adrenergic receptor (ADR) genotypes have been associated with adverse outcomes in heart failure. Our objective was to evaluate the association of ADR genotypes with post-Norwood outcomes in infants with hypoplastic left heart syndrome (HLHS).

Methods: Infants with HLHS participating in the Pediatric Heart Network SingleVentricle Reconstruction Trial underwent genotyping for 4 single-nucleotide polymorphisms in 3 ADR genes: ADRB1_231A/G, ADRB1_1165G/C, ADRB2_5318C/ $G$, and $A D R A 2 A \_2790 C / T$. The association of genotype with freedom from serious adverse events (SAEs) (death, transplant, extracorporeal membrane oxygenation, cardiopulmonary resuscitation, acute shunt failure, unplanned reoperations, or necrotizing enterocolitis) during 14 months' follow-up was assessed with Cox regression and the association with post-Norwood complications was assessed with Poisson regression. Models were adjusted for clinical and surgical factors.

Results: The study included 351 eligible patients ( $62 \%$ male; $83 \%$ white). The mean age at Norwood procedure was $5.6 \pm 3.6$ days. A total of 152 patients had SAEs during 14-month follow-up including 84 deaths and 10 transplants. ADRA2A_2790CC genotype had lower SAE-free survival compared with $C T$ / $T T$ genotypes during follow-up (Log rank test, $P=.02$ ), and this association was independent of clinical and surgical risk factors (adjusted Cox regression, hazard ratio $1.54[95 \%$ confidence interval $1.04,2.30] P=.033$ ). PostNorwood complication rate did not differ by genotype.

Conclusions: Infants with HLHS harboring ADR genotypes that are associated with greater catecholamine release or sensitivity had lower event-free survival after

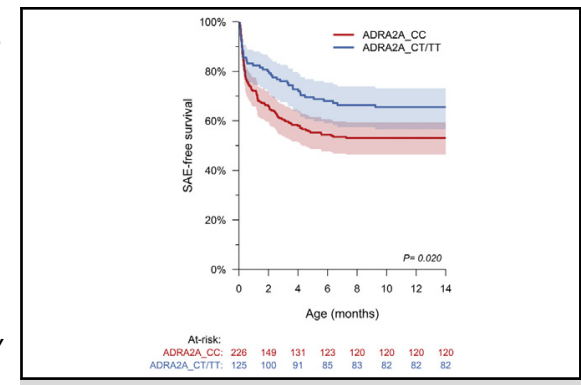

Kaplan-Meier plot: Lower serious adverse event-free survival with ADRA2A_7790CC genotype (log rank test $P=.020$ ).

\section{Central Message}

Variations in adrenergic receptor genes influence postoperative outcomes in infants with hypoplastic left heart syndrome undergoing staged palliation.

\section{Perspective}

Staged palliation for single-ventricle lesions is associated with significant morbidity and mortality. Patients with adrenergic receptor genotypes associated with augmented catecholamine signaling had lower freedom from serious adverse events after stage 1 palliation. Future studies should explore whether targeting adrenergic activation in those harboring risk genotypes can improve outcomes.

See Editorial Commentary page 1711

\footnotetext{
From the ${ }^{\mathrm{a}}$ Hospital for Sick Children, University of Toronto, and ${ }^{\mathrm{k}}$ Cardiovascular Data Management Centre, Hospital for Sick Children, Toronto, Ontario, Canada; ${ }^{b}$ New England Research Institute, Watertown, and 'Boston Children's Hospital, Boston, Mass; 'Children's Hospital of Los Angeles, Los Angeles, Calif; ${ }^{\mathrm{d} C o l u m b i a}$ University Medical Center, New York, NY; ${ }^{\mathrm{e}}$ Emory University, Atlanta, Ga; ${ }^{\mathrm{f}}$ Medical University of South Carolina, Charleston, SC; ${ }^{g}$ Children's Hospital of Wisconsin, Milwaukee, Wis; h University of Utah School of Medicine, Salt Lake City, Utah; ${ }^{\mathrm{i}}$ Duke University Medical Center, Durham, NC; ${ }^{\mathrm{j}}$ University of Michigan Health, Ann Arbor, Mich; and ${ }^{\mathrm{m}}$ Children's Hospital of Philadelphia, Philadelphia, $\mathrm{Pa}$.

Supported by grants HL068269, HL068270, HL068279, HL068281, HL068285, HL068288, HL068290, HL068292, HL109778, and HL085057 from the National Heart, Lung, and Blood Institute.

Clinical Trial Registry Number: NCT00115934

Numbers and Dates of IRB Approvals*

Hospital for Sick Children, 1000006285, February 11, 2005

Children's Hospital of Los Angeles, CCI-05-00038, September 5, 2008

Columbia University Medical Center, AAAB0870, January 12, 2005

Emory University, IRB00009510, November 10, 2005

Medical University of South Carolina, HR18084, May 6, 2008
}

Children's Hospital of Wisconsin, CHW 05/29, April 21, 2005 University of Utah School of Medicine, 13354, February 5, 2005 Duke University Medical Center, Pro00004594, April 5, 2003 University of Michigan Health, 41816, September 17, 2010 Boston Children's Hospital, 04-12-162, December 13, 2004 Children's Hospital of Philadelphia, IRB 05-004136, January 5, 2004

SVR Biorepository at University of Michigan Health, HUM00031665, September 3 , 2010

* These are original approval dates of trial participating sites, and of the SVR biorepository located at University of Michigan. All institutional review board approvals are active.

Received for publication Aug 4, 2016; revisions received June 6, 2017; accepted for publication June 20, 2017; available ahead of print July 19, 2017.

Address for reprints: Seema Mital, MD, Hospital for Sick Children, 555 University Ave, Toronto, Ontario M5G 1X8, Canada (E-mail: seema.mital@sickkids.ca). 0022-5223

Copyright () 2017 by The American Association for Thoracic Surgery. Published by Elsevier Inc. This is an open access article under the CC BY-NC-ND license (http:// creativecommons.org/licenses/by-nc-nd/4.0/).

http://dx.doi.org/10.1016/j.jtcvs.2017.06.041 


\section{Abbreviations and Acronyms}

$\begin{array}{ll}\text { ADR } & =\text { adrenergic receptor } \\ \text { HLHS } & =\text { hypoplastic left heart syndrome } \\ \text { PHN } & =\text { Pediatric Heart Network } \\ \text { RAAS } & =\text { renin-angiotensin-aldosterone system } \\ \text { RV } & =\text { right ventricle } \\ \text { RVEF } & =\text { right ventricular ejection fraction } \\ \text { SAE } & =\text { serious adverse event } \\ \text { SNP } & =\text { single-nucleotide polymorphism } \\ \text { SVR Trial } & \text { Single Ventricle Reconstruction Trial }\end{array}$

Scanning this $\mathrm{QR}$ code will take you to the appendices and supplemental table for this article.

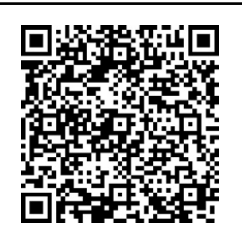

staged palliation. Excess catecholamine activation may adversely affect cardiovascular adaptation after the Norwood procedure. Future studies should explore whether targeting adrenergic activation in those harboring risk genotypes can improve outcomes. (ClinicalTrials.gov number NCT00115934) (J Thorac Cardiovasc Surg 2017;154:1703-10)

Single-ventricle lesions comprise more than $7 \%$ of all congenital heart defects, with hypoplastic left heart syndrome (HLHS) being the most common lesion. ${ }^{1,2}$ In HLHS, a single right ventricle (RV) acts as a systemic ventricle, whereas the left ventricle is hypoplastic or rudimentary. Patients with HLHS require multiple palliative surgeries to separate the pulmonary and systemic circulations with the first staged palliation, ie, the Norwood procedure, performed in the newborn period. Maintenance of systemic cardiac output after the Norwood procedure requires a balance between the systemic and pulmonary circulations and adequate RV function. Abnormal systemic and pulmonary vascular resistance and ventricular dysfunction are major contributors to maladaptation to a single-ventricle physiology. In one analysis, up to $40 \%$ of patients with staged palliation were noted to have some degree of heart failure. ${ }^{3}$

Single-ventricle patients have fragile hemodynamics and are especially vulnerable after cardiac surgery. The postoperative physiological stress response involves a surge in endogenous catecholamine production, which can have profound effects on cardiac function and vascular tone mediated by adrenergic receptors. Adrenergic receptors include presynaptic $\alpha 2 \mathrm{a}$ and $\alpha 2 \mathrm{c}$ receptors that inhibit norepinephrine release, cardiac $\beta 1$ receptors that mediate chronotropic and inotropic response to norepinephrine, and $\beta 2$ receptors that mediate vascular smooth muscle relaxation and response to $\beta$-blockers. ${ }^{4}$ Adrenergic upregulation is an important mechanism of cardiovascular adaptation during stress, particularly in the infant, in whom the circulation is highly catecholamine-dependent. ${ }^{5,6}$ Although acute upregulation is compensatory, chronic upregulation can have detrimental effects by increasing systemic and pulmonary vascular resistance and increasing myocardial oxygen demands, resulting in adverse cardiac remodeling and ventricular dysfunction. ${ }^{4,7-12}$ In children with dilated cardiomyopathy, $\alpha 2$ and $\beta 1$ upregulation and $\beta 2$ downregulation genotypes were associated with worse ventricular function, progression of heart failure, and acute hemodynamic decompensation. ${ }^{13}$ The impact of adrenergic receptor genotypes on adaptation to hemodynamic and surgical stress in infants with HLHS undergoing staged palliation is not known. We hypothesized that genetic modulation of receptor activity would alter catecholamine response and thereby influence postoperative clinical course. The purpose of our study was to evaluate whether genetic variants that upregulate adrenergic receptor activity adversely impact post-Norwood outcomes in infants with HLHS enrolled in the Single Ventricle Reconstruction Trial (SVR Trial).

\section{METHODS \\ Study Population}

This is an ancillary study that derives from the Pediatric Heart Network (PHN) SVR Trial, in which infants with HLHS $(\mathrm{n}=555)$ were enrolled from 15 North American centers between May 2005 and July 2008. The details of the study design, inclusion criteria, study assessments, as well as trial results have been published previously. ${ }^{14,15}$ In brief, inclusion criteria for the SVR Trial included a diagnosis of HLHS or a related single morphologic RV anomaly, planned Norwood procedure, and absence of a genetic or medical condition that would affect transplantfree survival. Infants were randomized to receive a modified BlalockTaussig shunt versus a right ventricle-pulmonary artery shunt as part of their Norwood procedure and were followed for 14 months with serial assessment. The study was approved by the local institutional review boards, and informed consent for study participation was obtained from the parents or legal guardians. Data collection included patient demographics and baseline characteristics, operative variables, hospitalization course, clinical outcomes, and echocardiographic assessment of right ventricular ejection fraction (RVEF). All echocardiograms were reviewed centrally by an independent observer at the echocardiography core laboratory. ${ }^{14,15}$

\section{Genotyping}

Buccal swab epithelial cells were collected at enrollment or during Norwood hospitalization with CytoSoft cytology brushes (Medical Packaging Corporation, Camarillo, Calif) after informed consent was obtained. Methods have been reported previously. ${ }^{16}$ Genomic DNA was extracted with a PureGene kit (Gentra Systems, Inc, Minneapolis, Minn) according to the manufacturer's protocol. Samples were retrieved from the PHN Biorepository for genotyping. Participants in the SVR Trial who did not 


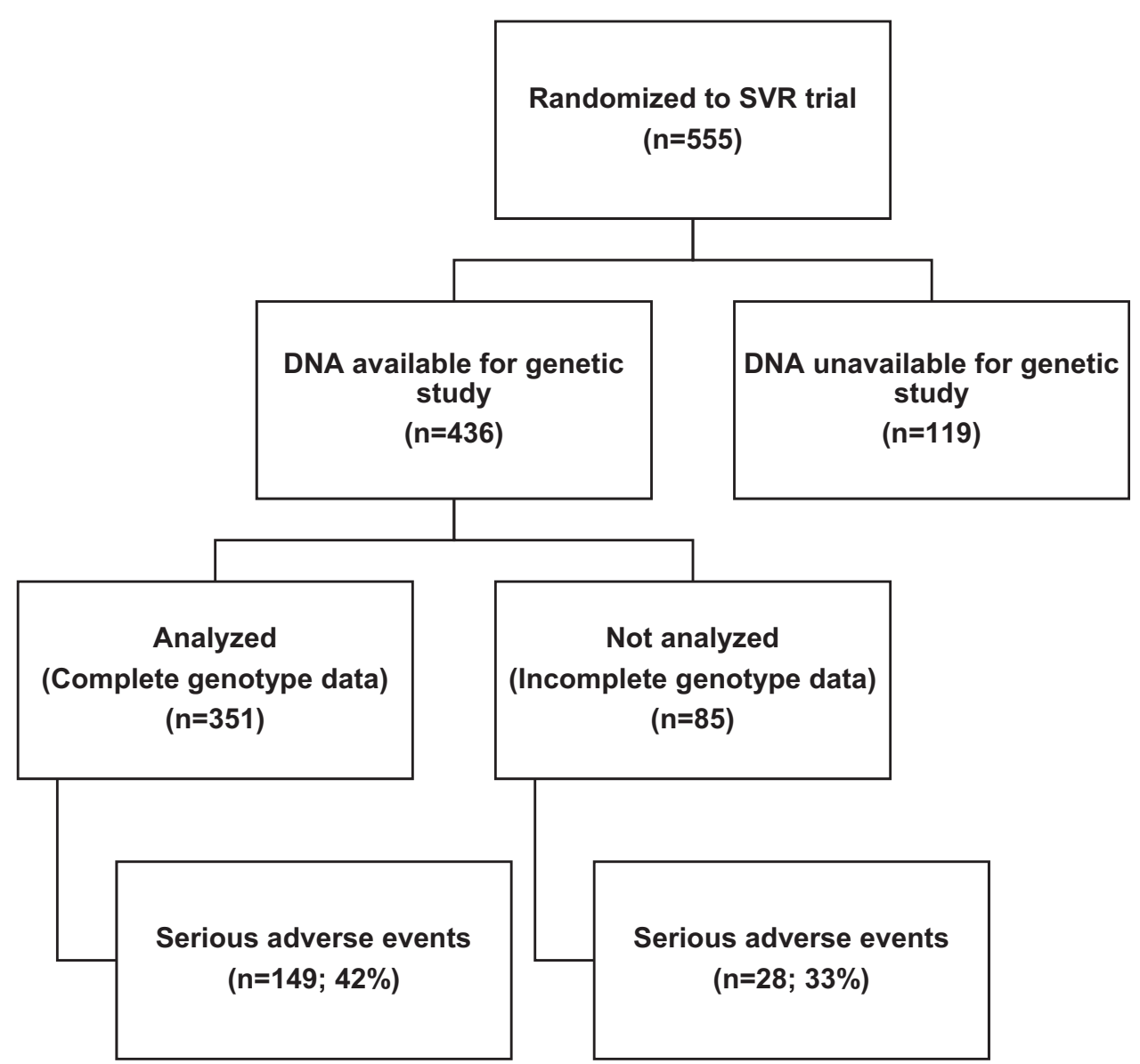

FIGURE 1. A consort flow diagram showing the outcomes in the complete and incompletely genotyped groups from patients randomized in the SVR Trial. SVR Trial, Single-Ventricle Reconstruction Trial.

consent to future testing of their samples were not included in the ancillary study. The ancillary study was approved by the PHN Ancillary Study Review Committee and by the University of Michigan Institutional Review Board.

Adrenergic receptor single-nucleotide polymorphisms (SNPs) were selected on the basis of previous association studies, functional effects, and population allele frequencies. ${ }^{13,17,18}$ Genotyping (Sequenom SNP) was performed for 4 SNPs in 3 adrenergic receptor (ADR) genes: a A/G missense variant at position 231 in ADRB1 resulting in a serine to glycine substitution (rs1801252), a C/G missense variant at position 1165 in ADRB1 resulting in a glycine to arginine substitution (rs1801253), a C/G missense variant at position 5318 in ADRB2 resulting in a glutamine to glutamic acid substitution (rs1042714), and a $\mathrm{C} / \mathrm{T} 3^{\prime}$ untranslated region variant at position 2790 in ADR2A (rs553668). Patients carrying a single copy of the variant allele or SNP (also known as minor allele) at the genetic locus were defined as having a heterozygous genotype, those with 2 copies of the variant allele as having a homozygous genotype, and those without a variant allele, ie,

TABLE 1. ADR variant frequencies

\begin{tabular}{|c|c|c|c|c|c|}
\hline Gene (SNP ID) & Nucleotide substitution & $\begin{array}{l}\text { Amino acid } \\
\text { substitution }\end{array}$ & Function by genotype & $\begin{array}{l}\text { SNP carrier } \\
\text { frequency }\end{array}$ & $\begin{array}{l}\text { HWE } \\
P \text { value }\end{array}$ \\
\hline$A D R B 1$ (rs1801252) & $231 \mathrm{~A} / \mathrm{G}$ (missense) & Ser49Gly & $\begin{array}{l}\text { GG: Greater basal adenylate } \\
\text { cyclase activity and lower } \\
\text { isoproterenol sensitivity }\end{array}$ & $32 \%$ & .717 \\
\hline$A D R B 1(\mathrm{rs} 1801253)$ & $1165 \mathrm{C} / \mathrm{G}$ (missense) & Gly389Arg & $\begin{array}{l}\text { CC: Increases } \beta 1 \text { receptor } \\
\text { sensitivity }\end{array}$ & $44 \%$ & .818 \\
\hline$A D R B 2$ (rs 1042714) & $5318 \mathrm{C} / \mathrm{G}$ (missense) & Gln27Glu & $\begin{array}{l}\text { GluGlu: Enhances response to } \beta \\
\text { adrenergic receptor antagonist }\end{array}$ & $62 \%$ & .972 \\
\hline$A D R A 2 A(\mathrm{rs} 553668)$ & $2790 \mathrm{C} / \mathrm{T}\left(3^{\prime} \mathrm{UTR}\right)$ & & $\begin{array}{l}\mathrm{CC} \text { : Increased norepinephrine } \\
\text { release }\end{array}$ & $36 \%$ & .918 \\
\hline
\end{tabular}

SNP, Single-nucleotide polymorphism; $H W E$, Hardy-Weinberg equilibrium; $A D R$, adrenergic receptor; $U T R$, untranslated region. 
TABLE 2. Patient characteristics and outcomes

\begin{tabular}{|c|c|c|c|c|c|}
\hline Characteristics & $\mathbf{n}$ & Complete genotyping & $\mathbf{n}$ & Incomplete genotyping & $P$ value* \\
\hline Sex, male, n (\%) & 351 & $220(62.7)$ & 85 & $56(65.9)$ & .62 \\
\hline Race, white, n (\%) & 351 & $288(82.1)$ & 85 & $68(80.0)$ & .44 \\
\hline Birth weight, kg & 351 & $3.13 \pm 0.53$ & 85 & $3.13 \pm 0.53$ & .96 \\
\hline Gestational age, wk & 344 & $38 \pm 1$ & 83 & $38 \pm 2$ & .38 \\
\hline Identifiable syndrome, n (\%) & 150 & $22(14.7)$ & 19 & $3(15.8)$ & 1.00 \\
\hline Aortic atresia, n (\%) & 351 & $215(61.3)$ & 85 & $50(58.8)$ & .71 \\
\hline Obstructed PVR, n (\%) & 351 & $10(2.8)$ & 85 & $1(1.2)$ & .70 \\
\hline Age at Norwood, d & 351 & $6 \pm 4$ & 85 & $6 \pm 4$ & .12 \\
\hline Age at stage 2 palliation, $\mathrm{d}$ & 276 & $162 \pm 53$ & 75 & $164 \pm 77$ & .78 \\
\hline Total CPB time, min & 351 & $139 \pm 51$ & 85 & $140 \pm 43$ & .86 \\
\hline DHCA time, min & 324 & $33 \pm 21$ & 76 & $31 \pm 18$ & .27 \\
\hline MBTS, n (\%) & 351 & $170(48.4)$ & 85 & $44(51.8)$ & .63 \\
\hline RVPAS, n (\%) & 351 & $183(52.1)$ & 85 & $43(50.6)$ & .81 \\
\hline \multicolumn{6}{|l|}{ Norwood course } \\
\hline Median hospital LOS, d & 351 & $24(15-42)$ & 85 & $22(15-32)$ & .35 \\
\hline Median ICU LOS, d & 255 & $15(9-33)$ & 52 & $13(9-24)$ & .65 \\
\hline $\begin{array}{l}\text { Patients with } \\
\text { complications, n (\%) }\end{array}$ & 351 & $278(79.2)$ & 85 & $63(74.1)$ & .31 \\
\hline $\begin{array}{l}\text { Number of complications } \\
\text { per patient }\end{array}$ & 351 & $3 \pm 3$ & 85 & $2 \pm 3$ & .25 \\
\hline Prestage II RVEF, \% & 195 & $44 \pm 9$ & 56 & $43 \pm 7$ & .47 \\
\hline \multicolumn{6}{|l|}{14 months' follow-up } \\
\hline Deaths, n (\%) & 351 & $84(23.9)$ & 85 & $11(12.9)$ & .028 \\
\hline $\begin{array}{l}\text { Norwood } \\
\text { hospitalization, n (\%) }\end{array}$ & 84 & $36(42.9)$ & 11 & $4(36.3)$ & \\
\hline $\begin{array}{l}\text { After Norwood } \\
\text { discharge, n (\%) }\end{array}$ & 84 & $48(57.1)$ & 11 & 7 (63.6) & \\
\hline Transplants, n (\%) & 351 & $10(2.8)$ & 85 & $2(2.4)$ & 1.00 \\
\hline $\begin{array}{l}\text { Norwood } \\
\text { hospitalization, n (\%) }\end{array}$ & 10 & $6(60)$ & 2 & $1(50)$ & \\
\hline $\begin{array}{l}\text { After Norwood } \\
\text { discharge, } \mathrm{n}(\%)\end{array}$ & 10 & $4(40)$ & 2 & $1(50)$ & \\
\hline $\begin{array}{l}\text { Serious adverse events, } \mathrm{n} \\
\quad(\%)\end{array}$ & 351 & $152(43.3)$ & 85 & $29(34.1)$ & .14 \\
\hline 14 mo RVEF, \% & 168 & $43 \pm 8$ & 48 & $42 \pm 7$ & .52 \\
\hline
\end{tabular}

$P V R$, Pulmonary venous return; $C P B$, cardiopulmonary bypass; $D H C A$, deep hypothermic circulatory arrest; $M B T S$, modified Blalock-Taussig shunt; $R V P A S$, right ventricle to pulmonary artery shunt; $L O S$, length of stay; $I C U$, intensive care unit; $R V E F$, right ventricular ejection fraction. ${ }^{*} P$ values were calculated with either the Fisher exact test or Student $t$ test.

carrying only the normal allele (also known as major allele) were defined as having a wild-type genotype.

Because variants in the renin-angiotensin-aldosterone signaling (RAAS) pathway genes have been associated previously with adverse ventricular remodeling in infants with single-ventricle lesions, genotyping also was performed for 4 SNPs and 1 insertion-deletion variant in 5 RAAS genes. The following were considered RAAS-upregulation genotypes based on our previous work: $A G T \_C C, A C E \_D D, A G T R 1 \_C C$, $C Y P 11 B 2 \_C C$, and $C M A 1 \_A A$. The $C Y P 11 B 2$ and $C M A 1$ variants were genotyped with Sequenom SNP genotyping and the AGTR1, AGT, and the $A C E$ insertion/deletion polymorphisms were genotyped with TaqMan primers and probes. For samples and SNPs that did not yield a valid result by Sequenom or TaqMan analysis, PCR amplification followed by Sanger sequencing was performed. The detailed genotyping methods, primers, and probes for the Sequenom SNP analysis, the Taqman analysis and for the PCR amplification or Sanger sequencing are listed in Appendix E1 and Table E1.

\section{Statistical Analysis}

Allele and genotype frequencies were determined to calculate HardyWeinberg equilibrium. All demographic and clinical data were expressed as frequencies, mean with standard deviations, or medians with interquartile ranges. The primary outcome was a composite of any serious adverse event (SAE) during a 14-month follow-up after the Norwood procedure and included death, transplant, need for postoperative extracorporeal membrane oxygenation, postoperative cardiopulmonary resuscitation, acute shunt failure, unplanned reoperations, or necrotizing enterocolitis. ${ }^{19,20}$ Secondary outcomes included frequency of post-Norwood complications 


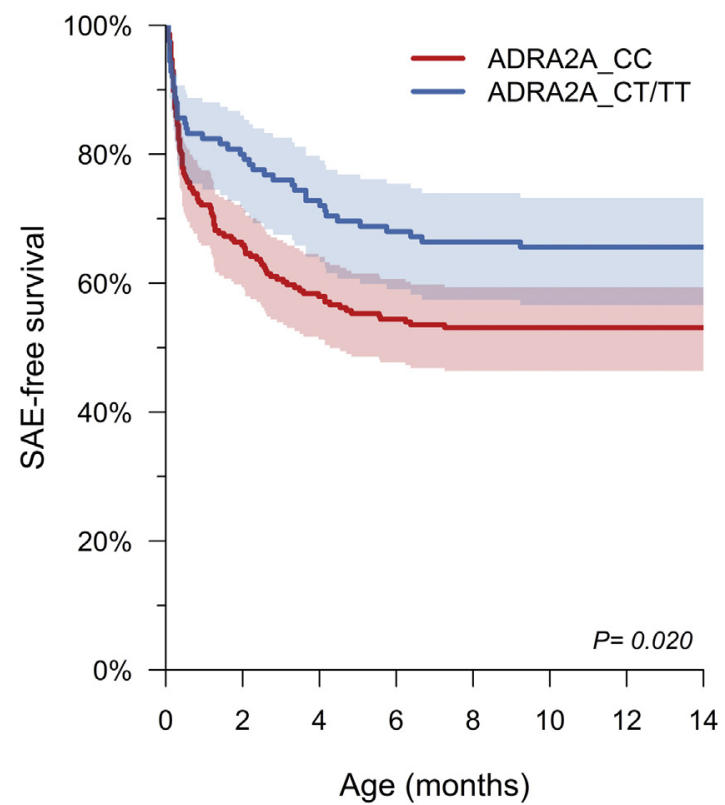

At-risk:

$\begin{array}{llllllll}\text { ADRA2A_CC: } 226 & 149 & 131 & 123 & 120 & 120 & 120 & 120\end{array}$

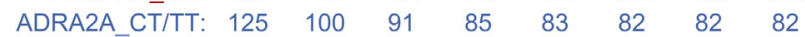

FIGURE 2. Freedom from serious adverse events post-Norwood by $A D R A 2 A$ genotype. Kaplan-Meier survival curve showing survival free from composite primary outcome stratified by ADRA2A_2790 genotype. The shaded bands represent $95 \%$ confidence intervals. Subjects with ADRA2A_2790CC genotype had lower survival free from SAEs compared with subjects with $C T / T T$ genotypes $(P=.02)$. $S A E$, Serious adverse event; $A D R$, adrenergic receptor.

up to hospital discharge from stage 2 surgery and RVEF during 14 months follow-up. Complications were defined as adverse events using the common terminology criteria for adverse events version 3.0 developed by the National Cancer Institute, National Institutes of Health, but that did not meet criteria for SAEs. ${ }^{20}$ Because post-Norwood hospital and intensive care unit length of stay were highly correlated with each other and with Norwood complication rate when analyzed using bootstrap Spearman rank correlation (data not shown), these outcomes were not analyzed separately.

ADR genotype associations were analyzed by comparing outcomes in homozygous or heterozygous SNP carriers versus wild-types using a dominant model. Freedom from the primary outcome was described with the Kaplan-Meier method with stratification by genotype. The log-rank test was used to assess between-stratum differences. Cox proportional hazard models adjusted for covariates of interest were used to test the association of the genotypes with the primary outcome. The proportional hazards assumption was verified using cumulative Martingale process plots. Associations were quantified by hazard ratios and reported along with their $95 \%$ confidence intervals. $P$ values were calculated based on Wald statistics. Poisson regression adjusted for overdispersion and for exposure time (number of days of hospitalization for Norwood procedure) was used to model the association of risk genotype with frequency of post-Norwood complications and results were presented as incidence rate ratios with $95 \%$ confidence intervals. A mixed model was used to assess for association of genotype with RVEF during 14 months' follow-up. All analyses were adjusted for sex, race, birth weight, gestational age, presence of aortic atresia or obstructed pulmonary venous return, presence of a genetic syndrome, age at Norwood procedure, total Norwood cardiopulmonary bypass time, deep hypothermic circulatory arrest time, type of shunt, and presence of a RAAS-upregulation genotype. ${ }^{21}$ The covariates selected were not found to exhibit significant collinearity. In regression models, when patients had missing data on the presence of identifiable syndromes, it was assumed that identifiable syndromes were not present. Observations with missing data in other variables were excluded from the models and this represented a very small percentage of the total cohort. All statistical analyses were performed with SAS v9.4 (SAS Institute, Cary, NC).

\section{RESULTS}

Of 555 patients in the SVR trial, 436 provided DNA and 351 had complete genotype data (ie, genotyping results for all 9 SNPs) and were included in the analysis (Figure 1). ADR genotype frequencies are shown in Table 1. All genotypes were in Hardy-Weinberg equilibrium. Patient clinical characteristics and outcomes in the group with complete versus incomplete genotypes are shown in Table 2. The only significant difference was a greater incidence of death in the completely genotyped cohort compared with the incompletely genotyped cohort. Incomplete genotyping was the result of technical issues such as low quality or quantity of DNA. The results hereby focus on the 351 subjects with complete genotype data.

We evaluated the association of ADR genotypes with the primary outcome of composite SAEs. Sixty-four percent of patients had the ADRA2A_2790CC genotype (wild-type). Kaplan-Meier analysis showed that patients with the $C C$

TABLE 3. Incidence rate of Norwood complications by ADR genotype

\begin{tabular}{|c|c|c|c|}
\hline \multirow{2}{*}{$\begin{array}{l}\text { Gene (SNP ID) } \\
A D R B 1\end{array}$} & \multicolumn{2}{|c|}{$\begin{array}{c}\text { Incidence rate of Norwood complications } \\
\text { (number/subject/day of hospitalization) }[95 \% \mathrm{CI}]\end{array}$} & \multirow[t]{2}{*}{$P$ value } \\
\hline & $\mathrm{AA}^{*}$ & GA/GG & \\
\hline (rs1801252) & $0.09[0.08-0.10]$ & 0.08 [0.07-0.09] & .38 \\
\hline$A D R B 1$ & $\mathrm{CC}^{*}$ & $\mathrm{CG} / \mathrm{GG}$ & \\
\hline (rs1801253) & $0.07[0.06-0.09]$ & $0.09[0.08-0.1]$ & .07 \\
\hline$A D R B 2$ & $\mathrm{CC}^{*}$ & $\mathrm{CG} / \mathrm{GG}$ & \\
\hline (rs1042714) & $0.09[0.08-0.09]$ & $0.08[0.07-0.10]$ & .70 \\
\hline$A D R A 2 A$ & $\mathrm{CC}^{*}$ & $\mathrm{CT} / \mathrm{TT}$ & \\
\hline (rs553668) & $0.08[0.07-0.10]$ & $0.08[0.07-0.10]$ & .93 \\
\hline
\end{tabular}

$S N P$, Single-nucleotide polymorphism; $C I$, confidence interval; $A D R$, adrenergic receptor. *Major allele: AA, CC, CC, and CC genotypes at the 4 loci represent wild-type genotypes; the remainder are polymorphic genotypes, ie, heterozygotes or homozygotes for the SNP. 
TABLE 4. Incidence rate ratio of Norwood complications by ADR genotype

\begin{tabular}{|c|c|c|c|}
\hline Gene (SNP ID) & Genotype & $\begin{array}{l}\text { ncidence rate ratio }[95 \% \\
\text { CI] of Norwood } \\
\text { complications }\end{array}$ & $P$ value* \\
\hline$A D R B 1$ (rs1801252) & AA vs $\mathrm{GA} / \mathrm{GG}^{\dagger}$ & $1.004[0.774-1.302]$ & .98 \\
\hline$A D R B 1(\mathrm{rs} 1801253)$ & $\mathrm{CC}$ vs $\mathrm{CG} / \mathrm{GG}^{\dagger}$ & $0.969[0.779-1.206]$ & .78 \\
\hline$A D R B 2(\mathrm{rs} 1042714)$ & $\mathrm{CC}$ vs $\mathrm{CG} / \mathrm{GG}^{\dagger}$ & 0.814 [0.638-1.037] & .10 \\
\hline$A D R A 2 A($ rs553668) & $\mathrm{CC}$ vs $\mathrm{CT} / \mathrm{TT}{ }^{\dagger}$ & $1.077[0.875-1.367]$ & .55 \\
\hline
\end{tabular}

SNP, Single-nucleotide polymorphism; $C I$, confidence interval; $A D R$, adrenergic receptor. *Poisson regression adjusted for covariates of interest and exposure time. $\nmid$ Major allele: AA, CC, CC, and CC genotypes at the 4 loci represent wild-type genotypes; the remainder are polymorphic genotypes, ie, heterozygotes or homozygotes for the SNP.

genotype had lower SAE-free survival during 14-month follow-up compared with CT/TT genotypes (log rank test: $P=.02$ ) (Figure 2). This association was independent of RAAS genotype and clinical and surgical risk factors (adjusted Cox regression: hazard ratio 1.549 [95\% confidence interval 1.04-2.30], $P=.033$ ). There was no synergistic adverse effect of multiple risk genotypes on outcomes.

Tables 3 and 4 describe the incidence rate of Norwood complications by genotype groups. Overall, $79 \%$ of patients had a post-Norwood complication with a median [95\% confidence interval] of 2 [1-4] complications per patient (Table 2). Complications by systems are shown in Table 5. The list of complications included for this trial have been published previously. ${ }^{20}$ Cardiac complications included arrhythmias, pericardial effusion, hypotension or hypertension, RV dysfunction, valvar insufficiency, and other. We evaluated the association of ADR genotypes with the rate of complications after the Norwood procedure using Poisson regression. All regression models were adjusted for demographic, clinical, and surgical risk factors as well as for RAAS genotypes and the Poisson regression was adjusted for exposure time. There were no significant differences in incidence rates of Norwood complications by genotype (Figure 3). ADR genotypes were not associated with significant difference in RV function during 14-month follow-up (data not shown) as assessed by

TABLE 5. Frequency of post-Norwood complications by systems

\begin{tabular}{lc}
\hline $\begin{array}{c}\text { Post-Norwood } \\
\text { complications by system }\end{array}$ & $\mathbf{N}=\mathbf{1 0 2 5}$ \\
\hline Cardiac & $239(23.3 \%)$ \\
Gastrointestinal & $100(9.8 \%)$ \\
Hematologic & $84(8.2 \%)$ \\
Infectious disease & $233(22.7 \%)$ \\
Neurologic & $41(4.0 \%)$ \\
Renal & $35(3.4 \%)$ \\
Respiratory & $249(24.3 \%)$ \\
Vascular & $5(0.5 \%)$ \\
\hline Other & $39(3.8 \%)$ \\
\hline
\end{tabular}

mixed-effects models adjusted for clinical and surgical factors.

\section{DISCUSSION}

In an era of precision medicine, there is a growing recognition of the importance of identifying not just clinical predictors but also genetic predictors of outcomes that can be used to individualize care and improve the safety and efficacy of medical and surgical interventions based on the unique genome and phenome of a patient. Previous studies have identified genetic variants that increase susceptibility to neurodevelopmental outcomes and adverse ventricular remodeling in single-ventricle patients undergoing staged palliation as well as in patients with other types of congenital heart disease undergoing surgical repair. ${ }^{16,21-24}$ In this study, we evaluated the association of genetic variants that increase ADR signaling with post-Norwood outcomes in infants with HLHS. Using genetic material collected during the trial, we demonstrated that the ADR genotype is an important predictor of outcomes of stage 1 palliation in infants with HLHS with lower SAE-free survival in patients harboring ADR risk genotypes. Although further study is required, these findings may have implications for individualizing perioperative management in this cohort based on genotype.

We evaluated 2 SNPs in the $A D R B 1$ gene and one in the $A D R B 2$ gene. The $A D R B 1 \_389 G G$ genotype has been associated previously with pediatric and adult heart failure, and the $A D R B 1 \_231 A A$ genotype is known to be associated with lower basal adenylate cyclase activity but increased sensitivity of the $\beta 1$ receptor to norepinephrine with enhanced sympathetic blood pressure response. ${ }^{17,25}$ Neither ADRB1 genotype nor the $A D R B 2$ genotype were associated with postoperative complications or SAEs in our study. ${ }^{10}$

The ADR2A receptor is important in regulating vascular tone as well as metabolic responses like insulin release from pancreatic cells and adipocyte metabolism in humans. Genetic variations lead to alterations in G-protein coupling and in agonist-promoted receptor phosphorylation and desensitization thereby modulating response to catecholamines. $^{12}$ The ADRA2A_2790CC genotype (wild-type) has been reported to cause reduced feedback inhibition of 


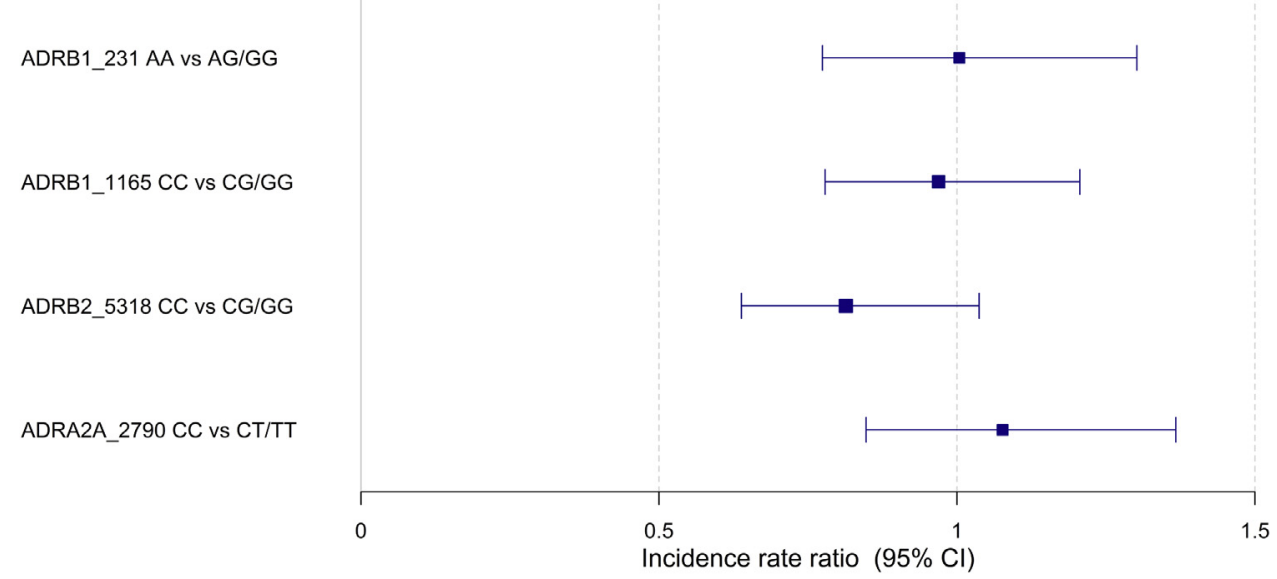

FIGURE 3. Incidence rate ratios of post-Norwood complications by ADR genotypes. Forest plot of IRRs of Norwood complications by genotype. The IRR is the ratio of the expected number of complications per patient per day of Norwood hospitalization in each genotype group. There were no significant differences in the IRRs of Norwood complications by genotype. IRR, Incidence rate ratio; $A D R$, adrenergic receptor.

norepinephrine and failure to inhibit sympathetic tone. ${ }^{26}$ Although we did not measure sympathetic tone, we found that patients with the $C C$ genotype had lower freedom from SAEs during 14-month follow-up compared with $C T / T T$ genotypes. One explanation for this finding is that a milieu of high-circulating catecholamines in patients with the $C C$ genotype may have resulted in increased vasomotor tone and an adverse effect on systemic output and organ perfusion, thereby increasing the risk of post-Norwood SAEs. The event-free survival curves diverged relatively sharply after the early postoperative period, at around 15 days (Figure 1). This suggests that although early events were more likely secondary to surgical complications that were similar in both genotype groups, later events were more likely influenced by genetic differences in adrenergic system-mediated adaptation to the Norwood circulation as well as recovery from complications. Overall, our findings suggest that genotypes associated with increased adrenergic neurohormonal activation and responsiveness may have a detrimental effect in the post-Norwood circulation.

A limitation of our study is that only a small number of candidate SNPs were analyzed. The DNA in the trial was acquired via buccal swabs, which required polymerase chain reaction amplification and did not yield sufficient quantity or quality of DNA for a more unsupervised approach using whole-exome sequencing. Nonetheless, the SNPs were selected carefully based on previous associations with outcomes in other pediatric cardiac studies. Also, RV myocardial samples and detailed hemodynamic data were not collected during the Norwood procedure for the trial precluding assessment of tissue adrenergic receptor expression, and of potential influence of the genotypes on metabolic and hemodynamic function. In addition, we were unable to evaluate the pharmacogenetic influences of the ADR genotypes with $\beta$-blocker response because less than $5 \%$ patients were receiving $\beta$-blocker therapy during follow-up. Also, the sample size of this study was reduced because of insufficient DNA or incomplete genotyping in the trial cohort. Nonetheless, the baseline characteristics of the genotyped and non-genotyped cohorts were similar excluding a survival bias in our study cohort.

In summary, ADR genotypes that enhance catecholamine levels and/or sensitivity increase the risk of SAEs in patients who survive beyond the first 2 weeks after the Norwood procedure. Further studies are needed to delineate the biological and hemodynamic effects of these genotypes and to validate these findings in additional cohorts. Pharmacologic modification of adrenergic receptors has been shown to positively influence outcome in other heart failure cohorts. $^{27-29}$ Although there is no evidence to support empiric $\beta$-blocker use in patients with HLHS, studies are needed to determine whether preoperative identification of these genetic subtypes can be used to target $\beta$-blockers and/or other forms of more aggressive systemic vasodilation post-Norwood to the subset with these risk genotypes.

\section{Conflict of Interest Statement}

Authors have nothing to disclose with regard to commercial support.

See Appendix E2 for a complete list of the Pediatric Heart Network Investigators.

\section{References}

1. Hoffman JIE, Kaplan S. The incidence of congenital heart disease. J Am Coll Cardiol. 2002;39:1890-900.

2. O'Leary PW. Prevalence, clinical presentation and natural history of patients with single ventricle. Prog Pediatr Cardiol. 2002;16:31-8.

3. Piran S, Veldtman G, Siu S, Webb GD, Liu PP. Heart failure and ventricular dysfunction in patients with single or systemic right ventricles. Circulation 2002;105:1189-94. 
4. Lymperopoulos A, Rengo G, Koch WJ. Adrenergic nervous system in heart failure: Pathophysiology and therapy. Circ Res. 2013;113:739-53.

5. Hislop AA, Mak JCW, Kelly D, Reader JA, Barnes PJ, Haworth SG. Postnatal changes in $\beta$-adrenoceptors in the lung and the effect of hypoxia induced pulmonary hypertension of the newborn. Br J Pharmacol. 2002;135:1415-24.

6. Whitsett JA, Noguchi A, Moore JJ. Developmental aspects of alpha- and betaadrenergic receptors. Semin Perinatol. 1982;6:125-41.

7. Brouri F, Hanoun N, Mediani O, Saurini F, Hamon M, Vanhoutte PM, et al. Blockade of $\beta 1$ - and desensitization of $\beta 2$-adrenoceptors reduce isoprenalineinduced cardiac fibrosis. Eur J Pharmacol. 2004;485:227-34.

8. Engelhardt S, Hein L, Wiesmann F, Lohse MJ. Progressive hypertrophy and heart failure in $\beta 1$-adrenergic receptor transgenic mice. Proc Natl Acad Sci USA. 1999; 96:7059-64.

9. Mann DL, Kent RL, Parsons B, Cooper G. Adrenergic effects on the biology of the adult mammalian cardiocyte. Circulation. 1992;85:790-804.

10. Nikolaev VO, Moshkov A, Lyon AR, Miragoli M, Novak P, Paur H, et al. Beta2adrenergic receptor redistribution in heart failure changes camp compartmentation. Science. 2010;327:1653-7.

11. Todd GL, Baroldi G, Pieper GM, Clayton FC, Eliot RS. Experimental catecholamine-induced myocardial necrosis: Morphology, quantification and regional distribution of acute contraction band lesions. J Mol Cell Cardiol. 1985; 17:317-38.

12. Xu J, He J, Castleberry AM, Balasubramanian S, Lau AG, Hall RA. Heterodimerization of $\alpha 2 \mathrm{a}$ - and $\beta 1$-adrenergic receptors. J Biol Chem. 2003;278:10770-7.

13. Reddy S, Fung A, Manlhiot C, Selamet Tierney ES, Chung WK, Blume E, et al. Adrenergic receptor genotype influences heart failure severity and beta-blocker response in children with dilated cardiomyopathy. Pediatr Res. 2015;77:363-9.

14. Ohye RG, Sleeper LA, Mahony L, Newburger JW, Pearson GD, Lu M, et al Comparison of shunt types in the Norwood procedure for single-ventricle lesions. N Engl J Med. 2010;362:1980-92.

15. Ohye RG, Gaynor JW, Ghanayem NS, Goldberg CS, Laussen PC, Frommelt PC, et al. Design and rationale of a randomized trial comparing the Blalock-Taussig and right ventricle-pulmonary artery shunts in the Norwood procedure. J Thorac Cardiovasc Surg. 2008;136:968-75.

16. Gaynor JW, Kim DS, Arrington CB, Atz AM, Bellinger DC, Burt AA, et al. Validation of association of the apolipoprotein e $\varepsilon 2$ allele with neurodevelopmental dysfunction after cardiac surgery in neonates and infants. J Thorac Cardiovasc Surg. 2014;148:2560-8.

17. Small KM, Wagoner LE, Levin AM, Kardia SLR, Liggett SB. Synergistic polymorphisms of $\beta 1$ - and $\alpha 2 \mathrm{c}$-adrenergic receptors and the risk of congestive heart failure. N Engl J Med. 2002;347:1135-42.

18. Sawczuk M, Maciehewska-Karlowska A, Cieszczyk P. A single nucleotide polymorphism rs553668 in the adra2a gene and the status of polish elite endurance athletes. Trends Sport Sci. 2013;1:30-5.
19. Ohye R, Schonbeck J, Eghtesady P, Laussen P, Pizarro C, Shrader P, et al. Cause, timing, and location of death in the Single Ventricle Reconstruction trial. J Thorac Cardiovasc Surg. 2012;144:907-14.

20. Virzi L, Pemberton V, Ohye RG, Tabbutt S, Lu M, Atz TC, et al. Reporting adverse events in a surgical trial for complex congenital heart disease: the Pediatric Heart Network experience. J Thorac Cardiovasc Surg. 2011;142: $531-7$.

21. Tabbutt S, Ghanayem N, Ravishankar C, Sleeper L, Cooper D, Frank DU, et al. Risk factors for hospital morbidity and mortality after the Norwood procedure: a report from the Pediatric Heart Network Single Ventricle Reconstruction trial. J Thorac Cardiovasc Surg. 2012; 144:882-995.

22. Mital S, Chung WK, Colan SD, Sleeper LA, Manlhiot C, Arrington $\mathrm{CB}$, et al. Renin-angiotensin-aldosterone genotype influences ventricular remodeling in infants with single ventricle. Circulation. 2011;123:2353-62.

23. Kaufman B, Auerbach S, Reddy S, Manlhiot C, Deng L, Prakash A, et al. Raas gene polymorphisms influence progression of pediatric hypertrophic cardiomyopathy. Hum Genet. 2007;122:515-23.

24. Kim DS, Kim JH, Burt AA, Crosslin DR, Burnham N, McDonald-McGinn DM, et al. Patient genotypes impact survival after surgery for isolated congenital heart disease. Ann Thorac Surg. 2014;98:104-11.

25. Mason DA, Moore JD, Green SA, Liggett SB. A gain-of-function polymorphism in a g-protein coupling domain of the human $\beta 1$-adrenergic receptor. $J$ Biol Chem. 1999;274:12670-4.

26. Gilsbach R, Schneider J, Lother A, Schickinger S, Leemhuis J, Hein L. Sympathetic $\alpha 2$-adrenoceptors prevent cardiac hypertrophy and fibrosis in mice at baseline but not after chronic pressure overload. Cardiovasc Res. 2010;86:432-44.

27. Truijen J, de Peuter OR, Kim Y, Bogaard B, Wouter EK, Kamphuisen PW, et al. Beta2-adrenergic receptor genotype influences the effect of nonselective vs. selective beta-blockade on baroreflex function in chronic heart failure. Int J Cardiol. 2011;153:230-2.

28. de Groote P, Lamblin N, Helbecque N, Mouquet F, Mc Fadden E, Hermant X, et al. The impact of beta-adrenoreceptor gene polymorphisms on survival in patients with congestive heart failure. Eur J Heart Fail. 2005; 7:966-73.

29. Jeewa A, Manickaraj AK, Mertens L, Manlhiot C, Kinnear C, Mondal T, et al. Genetic determinants of right-ventricular remodeling after Tetralogy of Fallot repair. Pediatr Res. 2012;72:407-13.

Key Words: genetics, hypoplastic left heart syndrome, congenital heart surgery, adrenergic receptors 


\section{APPENDIX E1. SUPPLEMENTAL GENOTYPING METHODS}

Sequenom SNP typing for the ADR SNPs was performed by the University of Michigan DNA Sequencing Core. Assays were designed with standard Sequenom software (Sequenom, San Diego, Calif; both online Assay Design Suite tools and desktop Assay Design 4.0) and performed using a Sequenom MassARRAY Compact instrument, according to manufacturer's standard protocols. Results were processed to generate single-nucleotide polymorphism (SNP) calls automatically, using Sequenom TyperAnalyzer software, and then manually reviewed by the operator to validate the allele calls. Automatic SNP calls that were of concern, based on questionable spectra, were removed. Sequenombased SNP typing was successful in ADRB2 (rs1042714) in 372 of 384 subjects, in ADRA2 (rs553668) in 362 of 384 subjects, in ADRB1 (rs1801253) in 338 of 384 subjects, and in ADRB1 (rs1801252) in 320 of 384 subjects.

Genotyping for the ACE I/D polymorphism was performed using a TaqMan assay as previously described. ${ }^{\mathrm{E} 1}$ Reactions were carried out in 96-well microtiter plates in a CFX96 Real Time System (Bio-Rad Laboratories, Hercules, Calif). The assay volume of $22 \mu \mathrm{L}$ consisted of $11 \mu \mathrm{L}$ of 2x Absolute QPCR ROX mix (ABgene), $150 \mathrm{nmol} / \mathrm{L}$ each primer (ACE111, ACE112, ACE113), 75 nmol/L FamACE100 (Deletion allele specific probe) and $150 \mathrm{nmol} / \mathrm{L}$ VIC-ACE100 (Insertion allele-specific probe), and $1 \mu \mathrm{L}$ of DNA $(\sim 50 \mathrm{ng})$. After denaturation for 10 minutes at $95^{\circ} \mathrm{C}$, amplification involved 45 cycles of denaturation at $95^{\circ} \mathrm{C}$ for 15 seconds, and primer annealing and extension at $57^{\circ} \mathrm{C}$ for 1 minute. Genotyping for the AGTR 1 and AGT SNPs also were performed using the CFX96 Real Time System (Bio-Rad). The assay volume of $5 \mu \mathrm{L}$ consisted of $2.5 \mu \mathrm{L}$ of $2 \mathrm{x}$ TaqMan Universal PCR reaction mix no AmpErase UNG (Thermo Fisher Scientific, Waltham, Mass), $0.125 \mu \mathrm{L}$ of SNP-specific 40x primer/probe reaction mix (Thermo Fisher Scientific), and $0.5 \mu \mathrm{L}$ of DNA ( $25 \mathrm{ng}$ ). Amplification involved 40 cycles of denaturation at $95^{\circ} \mathrm{C}$ for 15 seconds and primer annealing and extension at $60^{\circ} \mathrm{C}$ for 1 minute. Subject samples were run along with controls representing the possible genotypes for each assay as well as a no template control. Postamplification analysis of the genotypes at each codon was performed with the allelic discrimination analysis module of the CFX Manager Software V. 3.1 (Bio-Rad).

For those samples and SNPs that did not yield a valid result by Sequenom or TaqMan analysis, polymerase chain reaction (PCR) amplification followed by Sanger sequencing was performed. PCR primers were selected with the LaserGene Primer Select Program (DNASTAR Inc, Madison, Wis). A $12-\mu \mathrm{L}$ PCR was set up for each DNA sample to be tested. Each $12-\mu \mathrm{L}$ PCR contained 10 to $40 \mathrm{ng}$ of genomic patient or control DNA (1 $\mu \mathrm{L}), 1 \mu \mathrm{L}$ of $1.5 \mathrm{pmol}$ forward primer, $1 \mu \mathrm{L}$ of 1.5 pmol reverse primer, $3 \mu \mathrm{L}$ of DNase/RNase free water, and $6 \mu \mathrm{L}$ of HotStarTaq polymerase mixture (QIAGEN, Inc, Valencia, Calif). PCR DNA amplification was performed on a thermal cycler (Bio-Rad My-Cycler; Bio-Rad Life Sciences) as previously described. ${ }^{\mathrm{E} 2}$ To summarize in brief, a touchdown PCR protocol was used as follows: initial denaturation at $94^{\circ} \mathrm{C}$ for 15 minutes, followed by 24 cycles with an annealing temperature decreasing $0.7^{\circ} \mathrm{C}$ per cycle, starting at $72^{\circ} \mathrm{C}$ for 30 seconds; denaturation at $94^{\circ} \mathrm{C}$ for 30 seconds, and extension at $72^{\circ} \mathrm{C}$ for 1 minute. An additional 32 cycles were added: $94^{\circ} \mathrm{C}$ for 30 seconds, $55^{\circ} \mathrm{C}$ for 30 seconds, $72{ }^{\circ} \mathrm{C}$ for 1 minute, with a final extension of $72 \mu \mathrm{C}$ for $10 \mathrm{mi}-$ nutes. Sanger sequencing of the amplicons were performed by the University of Michigan DNA Sequencing Core facility with an Applied Biosystems DNA Sequencer (Model 3730 XL). Each chromatogram was visually inspected with Applied Biosystems Sequence Scanner (v1.0) software to determine genotypes. Primers and probes for the Sequenom SNP analysis, the Taqman analysis, and for the PCR amplication/Sanger sequencing are listed in Table E1. Combining the Sequenom-based and the PCR-based results, SNP typing was successful in ADRB2 (rs1042714) in 384 of 384 subjects, in ADRA2 (rs553668) in 384 of 384 subjects, in ADRB1 (rs1801253) in 383 of 384 subjects, and in ADRB1 (rs1801252) in 383 of 384 subjects.

\section{APPENDIX E2}

National Heart, Lung, and Blood Institute: Gail Pearson, Victoria Pemberton, Rae-Ellen Kavey,* Mario Stylianou, Marsha Mathis.*

Network Chair: University of Texas Southwestern Medical Center, Lynn Mahony

Data Coordinating Center: New England Research Institutes, Lynn Sleeper (PI), * Sharon Tennstedt (PI), * Steven Colan, Lisa Virzi,* Patty Connell,* Victoria Muratov,* Lisa Wruck,* Minmin Lu,* Dianne Gallagher,* Anne Devine, ${ }^{*}$ Julie Schonbeck, Thomas Travison, * David F. Teitel

Core Clinical Site Investigators: Children's Hospital Boston, Jane W. Newburger (PI), Peter Laussen,* Pedro del Nido, Roger Breitbart, Jami Levine, Ellen McGrath, Carolyn Dunbar-Masterson, John E. Mayer, Jr., Frank Pigula, Emile A. Bacha,* Francis Fynn-Thompson; Children's Hospital of New York, Wyman Lai (PI), Beth Printz, Daphne Hsu,* William Hellenbrand,* Ismee Williams, Ashwin Prakash,* Seema Mital,* Ralph Mosca,* Darlene Servedio,* Rozelle Corda, Rosalind Korsin, Mary Nash*; (Children's Co-Chair), Chitra Ravishankar, Thomas Spray, Meryl Cohen, Marisa Nolan, Stephanie Piacentino, Sandra DiLullo,* Nicole Mirarchi; Cincinnati Children's Medical Center, D. Woodrow Benson (PI), Catherine Dent Krawczeski, * Lois Bogenschutz, Teresa Barnard, Michelle Hamstra, Rachel Griffiths, Kathryn Hogan, Steven Schwartz, * David Nelson, Pirooz Eghtesady*; North Carolina Consortium: Duke University, East Carolina University, Wake Forest 
University, Page A. W. Anderson (PI) - deceased, Jennifer Li (PI), Wesley Covitz, Kari Crawford,* Michael Hines,* James Jaggers,* Theodore Koutlas, Charlie Sang, Jr., Lori Jo Sutton, Mingfen Xu; Medical University of South Carolina, J.Philip Saul (PI), ${ }^{*}$ Andrew Atz, Girish Shirali, Scott Bradley, Eric Graham, Teresa Atz, Patricia Infinger; Primary Children's Medical Center and the University of Utah, Salt Lake City, Utah, L. LuAnn Minich (PI), John A. Hawkins-deceased, Michael Puchalski, Richard V. Williams, Peter C. Kouretas, Linda M. Lambert, Marian E. Shearrow, Jun A. Porter*; Hospital for Sick Children, Toronto, Brian McCrindle (PI), Joel Kirsh, Chris Caldarone, Elizabeth Radojewski, Svetlana Khaikin, Susan McIntyre, Nancy Slater; University of Michigan, Caren S. Goldberg (PI), Richard G. Ohye (Study Chair), Cheryl Nowak*; Children's Hospital of Wisconsin and Medical College of Wisconsin, Nancy S. Ghanayem (PI), James S. Tweddell,* Kathleen A. Mussatto, Michele A. Frommelt, Peter C. Frommelt, Lisa Young-Borkowski.

Auxiliary Sites: Children's Hospital Los Angeles, Alan Lewis (PI), Vaughn Starnes, Nancy Pike; The Congenital Heart Institute of Florida (CHIF), Jeffrey P. Jacobs (PI), James A. Quintessenza, Paul J. Chai, David S. Cooper,* J. Blaine John, James C. Huhta, Tina Merola, Tracey Griffith; Emory University, William Mahle (PI), Kirk Kanter, Joel Bond,* Jeryl Huckaby; Nemours Cardiac Center, Christian Pizarro (PI), Carol Prospero; Julie Simons, Gina Baffa,
Wolfgang A. Radtke; University of Texas Southwestern Medical Center, Ilana Zeltzer (PI), Tia Tortoriello,* Deborah McElroy, Deborah Town.

Angiography Core Laboratory: Duke University, John Rhodes, J. Curt Fudge*

Echocardiography Core Laboratories: Children's Hospital of Wisconsin, Peter Frommelt; Children's Hospital Boston, Gerald Marx.

Genetics Core Laboratory: Children's Hospital of Philadelphia, Catherine Stolle; University of Michigan, Mark Russell.

Protocol Review Committee: Michael Artman (Chair); Erle Austin; Timothy Feltes, Julie Johnson, Thomas Klitzner, Jeffrey Krischer, G. Paul Matherne.

Data and Safety Monitoring Board: John Kugler (Chair); Rae-Ellen Kavey, Executive Secretary; David J. Driscoll, Mark Galantowicz, Sally A. Hunsberger, Thomas J. Knight, Holly Taylor, Catherine L. Webb.

*No longer at the institution listed.

\section{E-References}

E1. Koch W, Latz W, Eichinger M, Ganser C, Schömig A, Kastrati A. Genotyping of the angiotensin I-converting enzyme gene insertion/deletion polymorphism by the TaqMan method. Clin Chem. 2005;51:1547-9.

E2. Gaynor JW, Kim DS, Arrington CB, Atz AM, Bellinger DC, Burt AA, et al. Validation of association of the apolipoprotein E $\varepsilon 2$ allele with neurodevelopmental dysfunction after cardiac surgery in neonates and infants. J Thorac Cardiovasc Surg. 2014;148:2560-6. 
TABLE E1. Primer sequences for genotyping ADR SNPs

\begin{tabular}{|c|c|c|}
\hline Gene & SNP & Primer sequences \\
\hline$A D R B 1$ & rs1801252 & \\
\hline \multirow[t]{3}{*}{ Sequenom } & Primer 1 & ACGTTGGATGCTGTCCACTGCTGAGACA \\
\hline & Primer 2 & ACGTTGGATGGTCGCCGCCCGCCTCGTT \\
\hline & Probe & gacaaTGCTGAGACAGCGGCTCGGGGC \\
\hline \multirow[t]{2}{*}{ PCR } & Primer 1 & AGCCCGGTAACCTGTCGT \\
\hline & Primer 2 & CACGATCACCAGCACATTG \\
\hline$A D R B 1$ & rs1801253 & \\
\hline \multirow[t]{3}{*}{ Sequenom } & Primer 1 & ACGTTGGATGCCTTCAACCCCATCATCTAC \\
\hline & Primer 2 & ACGTTGGATGAGCCCTGCGCGCGCAGCAGA \\
\hline & Probe & TCCGCAAGGCCTTCCAG \\
\hline \multirow[t]{2}{*}{ PCR } & Primer 1 & TCTTCAACTGGCTGGGCTAC \\
\hline & Primer 2 & GGCCCTACACCTTGGATTC \\
\hline$A D R B 2$ & rs 1042714 & \\
\hline \multirow[t]{3}{*}{ Sequenom } & Primer 1 & ACGTTGGATGAGACATGACGATGCCCATGC \\
\hline & Primer 2 & ACGTTGGATGAAGCCATGCGCCGGACCA \\
\hline & Probe & ACACCTCGTCCCTTT \\
\hline \multirow[t]{2}{*}{ PCR } & Primer 1 & GACCGCCTCTTCGTCTTCTTCAACTGG \\
\hline & Primer 2 & CGCGCCGGGCCCTACACCT \\
\hline$A D R A 2 A$ & rs553668 & \\
\hline \multirow[t]{3}{*}{ Sequenom } & Primer 1 & ACGTTGGATGGGATGGGGAGGGCAGGCAG \\
\hline & Primer 2 & ACGTTGGATGTTCCCCTTCCATTCCCAACT \\
\hline & Probe & gcagtGCTGCCCTTAGCATTTTTCTT \\
\hline \multirow[t]{2}{*}{ PCR } & Primer 1 & CCCAAGGCCAGGATTTCAACAT \\
\hline & Primer 2 & GGCGGGCGTCTGCTGCTC \\
\hline
\end{tabular}

$A D R$, Adrenergic receptor; $S N P$, single-nucleotide polymorphism; $P C R$, polymerase chain reaction. 